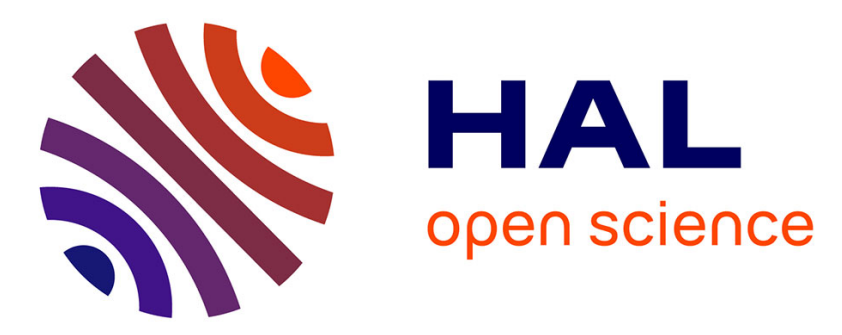

\title{
MAS dependent sensitivity of different isotopomers in selectively methyl protonated protein samples in solid state NMR
}

\author{
Kai Xue, Riddhiman Sarkar, Zdenek Tosner, Daniela Lalli, Carina Motz, \\ Benita Koch, Guido Pintacuda, Bernd Reif
}

\section{To cite this version:}

Kai Xue, Riddhiman Sarkar, Zdenek Tosner, Daniela Lalli, Carina Motz, et al.. MAS dependent sensitivity of different isotopomers in selectively methyl protonated protein samples in solid state NMR. Journal of Biomolecular NMR, 2019, 73 (10-11), pp.625-631. 10.1007/s10858-019-00274-0 . hal-02386226

\section{HAL Id: hal-02386226 \\ https://hal.science/hal-02386226}

Submitted on 4 Jan 2021

HAL is a multi-disciplinary open access archive for the deposit and dissemination of scientific research documents, whether they are published or not. The documents may come from teaching and research institutions in France or abroad, or from public or private research centers.
L'archive ouverte pluridisciplinaire HAL, est destinée au dépôt et à la diffusion de documents scientifiques de niveau recherche, publiés ou non, émanant des établissements d'enseignement et de recherche français ou étrangers, des laboratoires publics ou privés. 


\title{
MAS dependent Sensitivity of different Isotopomers in selectively Methyl protonated Protein Samples in solid State NMR
}

\author{
Kai Xue, ${ }^{a}$ Riddhiman Sarkar, ${ }^{a, b^{*}}$ Zdenek Tosner, ${ }^{c}$ Daniela Lalli, ${ }^{d}$ Carina Motz, ${ }^{b}$ Benita \\ Koch, ${ }^{b}$ Guido Pintacuda ${ }^{d, 1}$ and Bernd Reif ${ }^{a, b *}$
}

August 07, 2019

${ }^{a}$ Helmholtz-Zentrum München (HMGU), Deutsches Forschungszentrum für Gesundheit und Umwelt, Ingolstädter Landstr. 1, 85764 Neuherberg, Germany

${ }^{b}$ Munich Center for Integrated Protein Science (CIPS-M) at Department Chemie, Technische Universität München (TUM), Lichtenbergstr. 4, 85747 Garching,

\section{Germany}

${ }^{c}$ Department of chemistry, Faculty of Science, Charles University, Hlavova 8, 12842 Praha 2, Czech Republic

${ }^{d}$ Centre de Résonance Magnétique Nucléaire a Très hauts Champs (FRE 2034 -

CNRS, Ecole Normale Supérieure de Lyon, Université Claude Bernard Lyon 1), Université de Lyon, 5 rue de la Doua, 69100 Villeurbanne, France

\#Present address: Dipartimento di Scienze e Innovazione Tecnologica, Università del Piemonte Orientale Amedeo Avogadro, viale Teresa Michel, 15121 Alessandria, Italia

To whom correspondence should be addressed: reif@tum.de, riddhiman.sarkar@helmholtz-muenchen.de 


\begin{abstract}
Sensitivity and resolution together determine the quality of NMR spectra in biological solids. For high-resolution structure determination with solid-state NMR, protondetection emerged as an attractive strategy in the last few years. Recent progress in probe technology has extended the range of available MAS frequencies up to above $100 \mathrm{kHz}$, enabling the detection of resolved resonances from sidechain protons, which are important reporters of structure. Here we characterise the interplay between MAS frequency in the newly available range of $70-110 \mathrm{kHz}$ and proton content on the spectral quality obtainable on a $1 \mathrm{GHz}$ spectrometer for methyl resonances. Variable degrees of proton densities are tested on microcrystalline samples of the a-spectrin $\mathrm{SH} 3$ domain with selectively protonated methyl isotopomers $\left(\mathrm{CH}_{3}, \mathrm{CH}_{2} \mathrm{D}, \mathrm{CHD}_{2}\right)$ in a perdeuterated matrix. The experimental results are supported by simulations that allow the prediction of the sensitivity outside this experimental frequency window. Our results facilitate the selection of the appropriate labelling scheme at a given MAS rotation frequency.
\end{abstract}

Keywords: Solid State NMR, Magic Angle Spinning (MAS), Selective Deuteration, $\mathrm{CH} 3$ labelling, methyl isotopomers, Microcrystalline proteins 


\section{Introduction}

Direct detection of proton signals represents the most effective way to enhance NMR sensitivity (Maudsley et al. 1977) (Bodenhausen and Ruben 1980), (Ishii et al. 2001). In solids, however, the strong network of homonuclear dipolar couplings produces broad lines up to several kilohertz at moderate magic angle spinning (MAS) rates, with a consequent loss of spectral resolution (Maricq and Waugh 1979). Dilution of the proton content in a sample has been demonstrated as an effective strategy to retrieve narrow proton lines (McDermott et al. 1992) (Reif et al. 2001). However, both sensitivity and resolution are affected by the level of proton dilution depending on the MAS rate (Saalwächter 2005).

The maximum achievable frequency of sample spinning at the magic angle is inversely proportional to the diameter of the employed rotors (Samoson et al. 2005). Therefore, faster spinning implies smaller rotor volumes and less sample, and thus to start out with a reduced sensitivity. The effect is compensated by coil efficiency which is inversely related to coil diameter. In addition, protonated samples become accessible at ultra-fast rotation frequencies (Agarwal et al. 2014) (Andreas et al. 2016) (Bockmann et al. 2015). On the other hand, faster MAS is more effective in averaging ${ }^{1} \mathrm{H}$ dipolar interactions, and tolerate less stringent dilutions, reducing the associated signal loss.

For $4.0 \mathrm{~mm}$ diameter (10-20 $\mathrm{mg}$ sample), the maximum MAS frequency amounts to $18 \mathrm{kHz}$. Partial deuteration $(\mathrm{H}: \mathrm{D} \approx 10: 90)$ of exchangeable amide sites in an otherwise extensively deuterated environment is essential to obtain high proton spectral quality (Chevelkov et al. 2006; Reif 2012). Faster spinning (3.2 mm diameter, $23 \mathrm{kHz}$ ) allowed to increase the proton density at exchangeable sites to $~ 30 \%$. With the emergence of $1.3 \mathrm{~mm}$ probes (2 $\mathrm{mg}$ sample, maximum of $\sim 67 \mathrm{kHz} \mathrm{MAS}$ ), $100 \%$ protons at exchangeable amide sites (Lewandowski et al. 2011) in an otherwise deuterated sample yield optimal spectral quality for amide resonances (Schubeis et al. 2018; Stock et al. 2018; Vasa et al. 2019), opening the possibility for efficient detection of multiple triple-resonance correlations for site-specific backbone assignments (BarbetMassin et al. 2014; Knight et al. 2011; Nieuwkoop et al. 2015). Fully-protonated samples become accessible at above $100 \mathrm{kHz}$ MAS achievable in $0.7 \mathrm{~mm}$ probes (Andreas et al. 2016; Schubeis et al. 2018; Vasa et al. 2019). 
In comparison to the amide backbone, the proton density in the aliphatic sidechain is significantly higher. Fractional labelling of protons in the amino acid sidechains (Asami and Reif 2012, 2013; Asami et al. 2010) and/or inverse fractional deuteration (Mance et al. 2015) yield excellent spectral resolution at moderate MAS frequencies.

It is obvious from the few available studies that even at the highest MAS frequency commercially available today, dipolar dephasing is still a major impediment for protonated samples (Bockmann et al. 2015). Despite the recent examples of a constructive use of side-chain proton resonances in fully-protonated systems with frequencies of $\sim 110 \mathrm{kHz}$ (Andreas et al. 2016; Stanek et al. 2016), experiments and simulations indicate that sensitivity and resolution are destined to increase above MAS frequencies beyond $100 \mathrm{kHz}$ (Cala-De Paepe et al. 2017; Penzel et al. 2019), even for highly deuterated, $\mathrm{CH}_{3}$ methyl protonated samples (Agarwal et al. 2014; Penzel et al. 2015). In fact, MAS frequencies beyond $300 \mathrm{kHz}$ are needed to reach $80 \%$ of the maximum achievable sensitivity (Xue et al. 2018).

In solution NMR, $-\mathrm{CH}_{3}$ methyls yield the highest sensitivity with comparable resolution when comparing $-\mathrm{CHD}_{2},-\mathrm{CH}_{2} \mathrm{D}$ and $-\mathrm{CH}_{3}$ isotopomers. $\mathrm{CH}_{3}$ methyl labelling is therefore the preferred strategy to investigate large molecular weight systems (Sprangers and Kay 2007; Sprangers et al. 2007). In solids, the situation is quite different. Although $\mathrm{CH}_{3}$ has the highest proton density, intra-methyl as well as intermethyl dipole-dipole couplings are significant and efficient averaging by MAS is difficult to achieve (Xue et al. 2018).

In selectively methyl protonated samples, the $\mathrm{CH}_{3}$ isotopomer in principle yields a 3fold higher sensitivity in comparison to $\mathrm{CHD}_{2}$ labelling. At the same time, intra- and inter- methyl ${ }^{1} \mathrm{H},{ }^{1} \mathrm{H}$ dipolar interactions induce dipolar broadening that counters the advantage. A comparison of deuterated samples, with selectively labelled $\mathrm{CH}_{3}$ and $\mathrm{CHD}_{2}$ methyls at lle and Val has been carried out previously by Schanda and coworkers for the sedimented $468 \mathrm{kDa}$ dodecameric aminopeptidase TET2 (Kurauskas et al. 2016). The authors concluded that at $>60 \mathrm{kHz}$ MAS and $14.1 \mathrm{~T}\left(600 \mathrm{MHz}\right.$ for $\left.{ }^{1} \mathrm{H}\right)$ 
magnetic field the two schemes ( $\mathrm{CH} 3$ and $\mathrm{CHD} 2)$ yield comparable linewidths, with the $\mathrm{CH}_{3}$ labelling providing improved sensitivity.

We here address the question of which methyl isotopomer yields the highest sensitivity at the highest available MAS rates in a model, ordered microcrystalline sample using experiments and numerical simulations. It is found that a MAS frequency of $68 \mathrm{kHz}$ on average is needed to achieve a break-even in the sensitivity when $\mathrm{CHD}_{2}$ and $\mathrm{CH}_{3}$ labelled samples are compared.

We believe that the identification of the methyl isotopomer that yields the largest sensitivity at a given MAS rotation frequency will be useful for studies involving very large protein complexes, such as ribosomal complexes, for which sensitivity is limiting (Barbet-Massin et al. 2015) (Kurauskas et al. 2016) (Barbet-Massin et al. 2018) .

\section{Results}

We recorded ${ }^{1} \mathrm{H}$ detected $2 \mathrm{D}{ }^{13} \mathrm{C},{ }^{1} \mathrm{H}$ correlation spectra as a function of MAS frequency in the range of 70-106 kHz, employing Cross Polarization (CP) (Pines et al. 1973). We used two selectively methyl labelled $\left({ }^{13} \mathrm{CH}_{3},{ }^{13} \mathrm{CHD}_{2}\right)$ samples of the a-spectrin $\mathrm{SH} 3$ domain otherwise perdeuterated. Spectra for a sample containing ${ }^{13} \mathrm{CH}_{2} \mathrm{D}$ isotopomers were estimated using numerical simulations. 

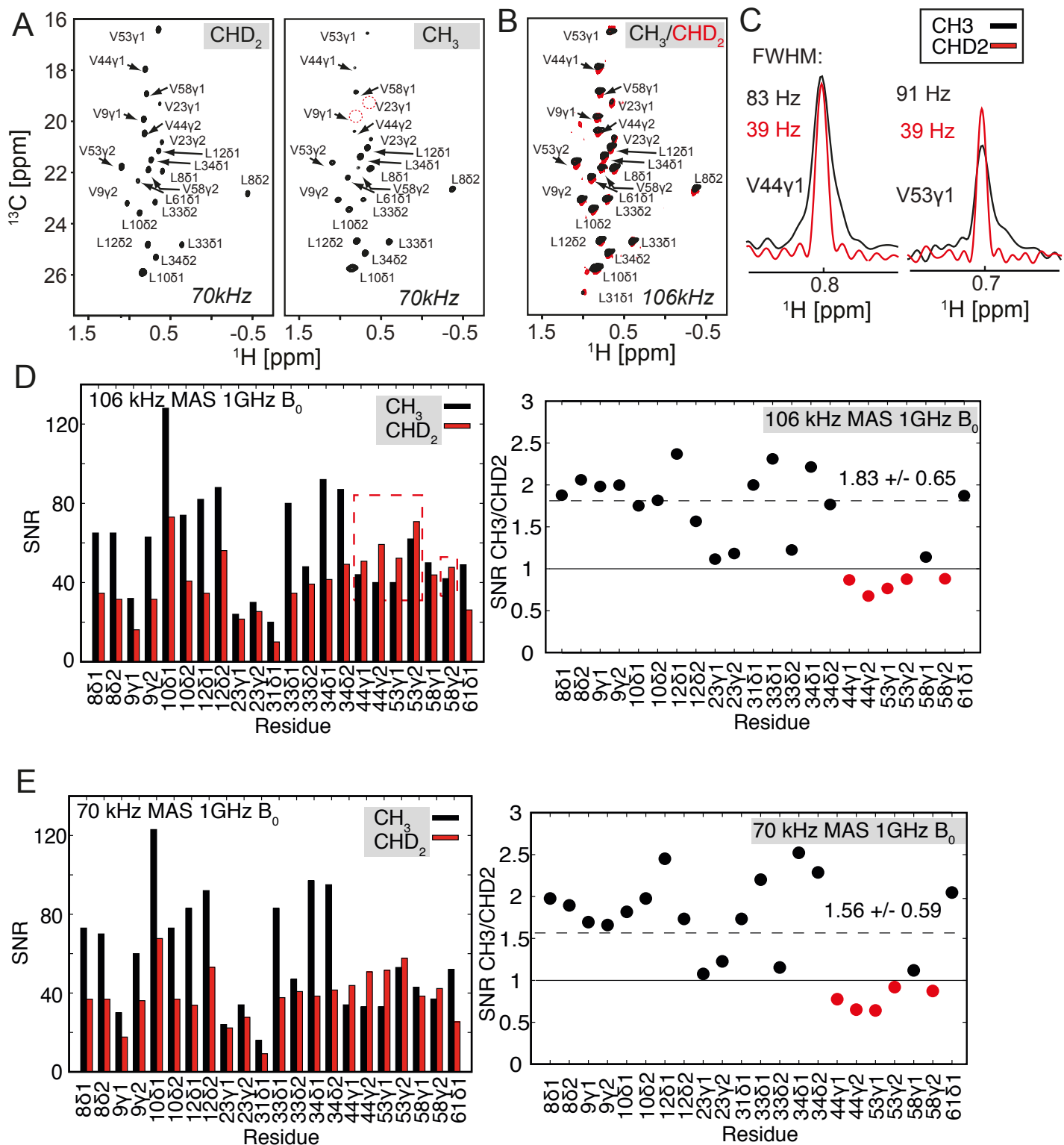

Figure 1. A) $\mathrm{CP}$ based $H S Q C$ spectra recorded for $\mathrm{CHD}_{2}$ and $\mathrm{CH}_{3}$ selectively methyl protonated a-spectrin $\mathrm{SH} 3$ domain samples. Experiments were performed using $70 \mathrm{kHz} M A S$, on a $1 \mathrm{GHz}$ spectrometer. Contour levels were set according to the same values, however accounting for the different amount of material in both samples. At this MAS frequency, not all cross peaks are observable for the $\mathrm{CH}_{3}$ labelled sample (e.g. V23 $\gamma 1, V 9 \gamma 1$, indicated by red circle). B) Superposition of CP based HSQC spectra recorded for $\mathrm{CHD}_{2}$ (red trace) and $\mathrm{CH}_{3}$ (black trace) selectively methyl protonated samples at $106 \mathrm{kHz}$ MAS, where all the cross peaks are visible. Contour levels were set to the same values accounting for the different amount of

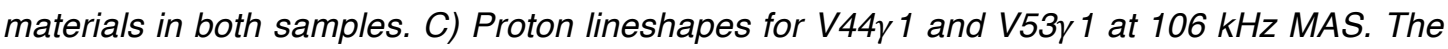
full width at half height $\mathrm{FWHH}$ ) of the proton methyl resonance of the $\mathrm{CH}_{3}$ selectively protonated $\mathrm{SH} 3$ sample $(\sim 90 \mathrm{~Hz})$ are much larger than those observed for the $\mathrm{CHD}_{2}$ labelled sample ( $35 \mathrm{~Hz}$ ). Absolute signal to noise ratio for all methyl cross peaks in $\mathrm{CHD}_{2}$ and $\mathrm{CH}_{3}$ selectively methyl protonated $\mathrm{SH} 3$ samples recorded at $106 \mathrm{kHz}(D)$ and $70 \mathrm{kHz}(E)$ MAS. The signal to noise ratio for the $\mathrm{CHD}_{2}$ sample was scaled according to amount of sample in each rotor $\left(\mathrm{CH}_{3}\right.$ : $C H D_{2}=1: 1.3$ ) as shown in Figure S4. Due to the fact that the proton content of the $\mathrm{CH}_{3}$ isotopomers is 3 times higher than the $\mathrm{CHD}_{2}$ isotopomers, we expect better sensitivity for the 
$\mathrm{CH}_{3}$ labelled sample. This is the case for the majority of the residues with the exception of 5 sites showing higher sensitivity in the $\mathrm{CHD}_{2}$ labelled sample.

In the following, we compare the experimental intensities from CP based HSQC spectra for $\mathrm{CH}_{3}$ and $\mathrm{CHD}_{2}$ labelled samples acquired at a MAS frequency of $106 \mathrm{kHz}$. As expected, we observe that the sensitivity of the methyl resonances is significantly increased for all methyl resonances in the $\mathrm{CH}_{3}$ labelled sample, with the exception of a few sites. To appreciate the effects of the proton network and the induced sitespecific dipolar broadenings, we compared the experimental $\mathrm{CH}_{3} / \mathrm{CHD}_{2}$ intensity ratios to the gain in sensitivity that is theoretically expected. The ratio of the cross-peak intensities for $\mathrm{CH}_{3}$ and $\mathrm{CHD}_{2}$ labelled samples $\left(\frac{I\left(\mathrm{CH}_{3}\right)}{I\left(\mathrm{CHD}_{2}\right)}\right)$ depends on number of protons, the respective ${ }^{1} \mathrm{H}$ and ${ }^{13} \mathrm{C}$ linewidth, as well as the transfer efficiencies $(\epsilon)$ in the following way:

$$
\frac{I\left(C H_{3}\right)}{I\left(C H D_{2}\right)}=3 * \frac{L W\left({ }^{1} H, C H D_{2}\right)}{L W\left({ }^{1} H, C H_{3}\right)} * \frac{L W\left({ }^{13} C, C H D_{2}\right)}{L W\left({ }^{13} C, C H_{3}\right)} * \frac{\epsilon\left(C H_{3}\right)}{\epsilon\left(C H D_{2}\right)}
$$

The transfer efficiency $(\epsilon)$ in the CP based experiments, as presented in this work, is related to $T_{1}^{\rho}$, whereas in the INEPT based experiments, the transfer efficiency strongly depends on the proton spin bath. $T_{2}^{\prime}$ typically increases with increased MAS rotation frequency (Asami and Reif 2012; Lewandowski et al. 2011). The ratio of ${ }^{1} \mathrm{H}$ and ${ }^{13} \mathrm{C}$ line widths of $\mathrm{CHD}_{2}$ versus $\mathrm{CH}_{3}$ labelled samples is on the order of 0.6 and 1.1, respectively (Figure S1). The ratio of the transfer efficiencies amounts to 1.45 (Figure S1). Accounting for all experimental parameters, we expect an increase of the intensities for the $\mathrm{CH}_{3}$ labelled sample by inserting experimental values in equation 1 as follows: $\frac{I\left(\mathrm{CH}_{3}\right)}{I\left(\mathrm{CHD}_{2}\right)}=3^{\star} 0.6^{*} 1.1^{*}(1 / 1.45) \sim 1.33$ at a MAS rotation frequency of $106 \mathrm{kHz}$. This is in good agreement with the experimental intensity ratios represented in Figure 1D. Of note, we consider negligible contribution of heterogeneity of magnetic field and sample to linewidths, which can be significant for samples such as amyloid fibrils or samples with local structural disorders.

Next, we compared the $\mathrm{CH}_{3} / \mathrm{CHD}_{2}$ intensity ratios with the $d^{R S S}$ values extracted from the X-ray structure of the a-spectrin SH3 domain. Following the convention of Zorin et al. (Zorin et al. 2006), $d^{R S S}$ refers to the square root of the sum of squared dipolar couplings: 


$$
d_{i}^{R S S}=\frac{\mu_{0}}{4 \pi} \gamma_{H}^{2} \sqrt{\sum_{j}\left(\frac{1}{r_{i, j}^{3}}\right)^{2}}
$$

$d^{R S S}$ is a proxy for the strength of the dipolar coupling network. The $d^{R S S}$ values have been calculated using the X-ray structure of the a-spectrin SH3 domain (PDB-ID: 2nuz) (Chevelkov et al. 2007). In the calculation, a distance cut-off of $15 \AA$ has been employed. As indicated schematically in Figure 2A, the number of potential protonproton interactions increases more than quadratically with the number of protons in the respective isotopomer. Figure $2 \mathrm{~B}$ shows the $\mathrm{CH}_{3} / \mathrm{CHD}_{2}$ intensity ratios correlated with the respective $d^{R S S}$ values.

A Intra Inter B

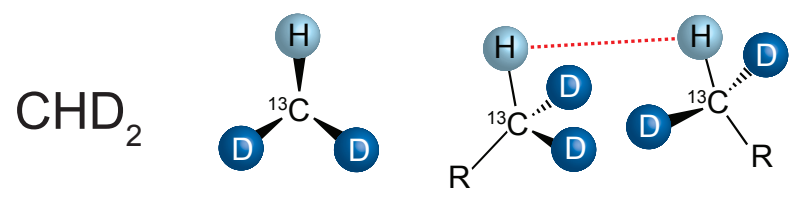
\# interactions: $1 * 0+1=1$<smiles>[2H][13CH][10BH]</smiles>

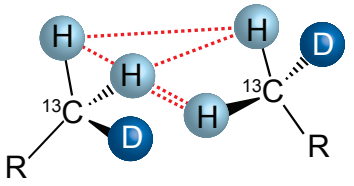
\# interactions: $2 * 1+4=6$<smiles>[B]C1C[18O]1</smiles>

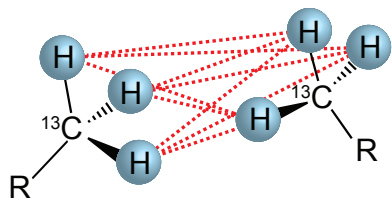
心 ${ }_{0}^{3}$

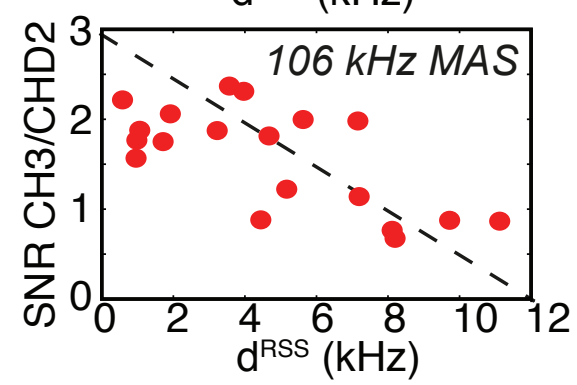

\# interactions: $3^{*} 2+9=15$

Figure 2. (A)Schematic representation of the dipolar coupling network for $\mathrm{CH}_{3}, \mathrm{CH}_{2} \mathrm{D}$ and $\mathrm{CHD}_{2}$ selectively protonated methyl groups. The number of expected ${ }^{1} \mathrm{H}^{1} \mathrm{H}$ dipolar interactions is indicated below each scheme. (B) Correlation between the experimental $\mathrm{CH}_{3} / \mathrm{CHD}_{2}$ intensity ratio and the effective dipolar coupling $d^{\text {RSS }}$. For the $\mathrm{CHD}_{2}$ selectively methyl protonated sample, $d^{\text {RSS }}$ has been calculated using a distance cut-off of $15 \AA$. For some leucine residues, the ${ }^{1} \mathrm{H}-{ }^{1} \mathrm{H}$ inter dipolar coupling is close to 0 . For those residues, the sensitivity gain from $\mathrm{CHD}_{2}$ to $\mathrm{CH}_{3}$ is close to the maximum value of 3 .

The distance between two protons in a methyl group is on the order of $1.79 \AA$, corresponding to a dipole-dipole coupling of $\sim 21 \mathrm{kHz}$. Assuming a rigid $\mathrm{CH}_{3}$ group, the total intramethyl $d^{R S S}$ is $\sim 51.4 \mathrm{kHz}\left(=\sqrt{3^{*}} \sqrt{2}{ }^{*} 21 \mathrm{kHz}\right)$. Due to the fast methyl group 
rotation, the anisotropic interactions are scaled by a factor of $-1 / 2$, yielding an averaged value of $\sim 26 \mathrm{kHz}$. For $\mathrm{CH}_{3}$, the inter-methyl contribution to $d^{R S S}$ varies between 0 and $36 \mathrm{kHz}$ (corresponding to a ${ }^{1} \mathrm{H}-{ }^{1} \mathrm{H}$ distance of $2.13 \AA$ ). For $\mathrm{CHD}_{2}, 1 / 9$ of these interactions remain, and $d^{R S S}$ is reduced to a value on the order of $0-12 \mathrm{kHz}$. The $d^{R S S}$ values in Figure 2B account only for the inter-methyl dipolar contributions. We find that the peak intensity ratios correlate rather well with the magnitude of the proton dipolar network.

Subsequently, we compared the $\mathrm{CH}_{3} / \mathrm{CHD}_{2}$ intensity ratio to explicit simulations carried out using the program SIMPSON (Bak et al. 2000; Tošner et al. 2014). Simulations and normalization of the experimental intensities was done as described previously (Xue et al. 2017; Xue et al. 2018). In brief, simulated and experimental intensities are related with the equation:

$$
\operatorname{INT}_{j}^{\exp }(i)=\kappa_{j} I N T_{j}^{\operatorname{sim}}(i) \epsilon_{j}
$$

where $\kappa_{j}$ is an empirical fitting factor that is determined for each experiment. The index $j$ denotes the MAS rotation frequency. $\epsilon_{j}$ describes the magnetization transfer efficiency at the MAS frequency $j$. In the following, we have employed cross polarization for magnetization transfer. $I N T_{j}^{\operatorname{sim}}(i)$ and $I N T_{j}^{\text {exp }}(i)$ are cross peak intensities from simulation and experiment respectively and $i$ is a residue specific index. Intensities for the $\mathrm{CH}_{3}$ and $\mathrm{CHD}_{2}$ labelled samples were normalized to 100 and $100 / 3$, respectively. In the simulation, each methyl group was assumed to be interacting with the two closest methyl groups in the X-ray structure (i.e. the spin system to be simulated contained up to 9 spins). Methyl rotations were considered by scaling the intra-methyl ${ }^{1} \mathrm{H}-{ }^{13} \mathrm{C}$ and ${ }^{1} \mathrm{H}-{ }^{1} \mathrm{H}$ dipolar coupling by $1 / 3$ and $-1 / 2$, respectively.

Simulated intensity build-up curves for the three labelling schemes $\left(-\mathrm{CH}_{3},-\mathrm{CH}_{2} \mathrm{D}\right.$, $\mathrm{CHD}_{2}$ ) are represented in Figure $3 \mathrm{~A}$. The simulations are superimposed with experimental data (shown in red) for $\mathrm{CH}_{3}$ and $\mathrm{CHD}_{2}$ labelled samples. In Figure 3A, two residues have been selected that represent methyl groups in a dilute (L34) and a dense (V44) proton network. The signal intensities as a function of MAS frequency are shown in Figure S2. Individual simulated $1 \mathrm{D}-{ }^{1} \mathrm{H}$ spectra are shown in Figure 3B. 

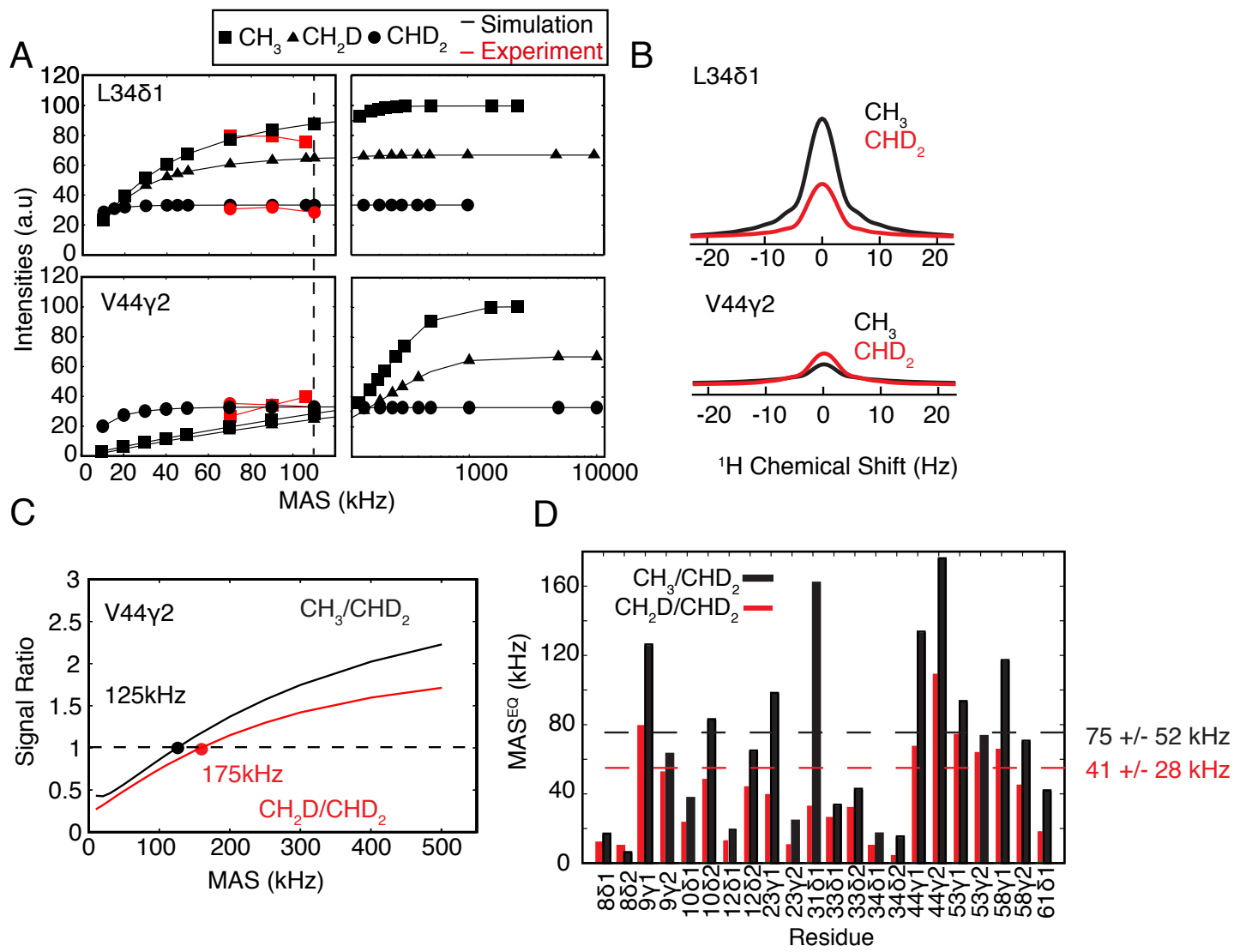

Figure 3. A) Cross peak intensity build-up curves for $\mathrm{L} 34 \delta 1$ and $\mathrm{V} 44 \mathrm{Y}$ in the a-spectrin $\mathrm{SH} 3$ domain as a function of the MAS frequency for $\mathrm{CHD}_{2}, \mathrm{CH}_{2} \mathrm{D}$ and $\mathrm{CH}_{3}$ selectively protonated samples. Residues V44 and L34 are embedded in differing proton networks and experience different effective proton dipolar couplings $d^{\mathrm{RSS}}$. Experimental intensities were corrected for $\mathrm{CH}_{3}$ and $\mathrm{CHD}_{2}$ with respect to the amount of protein in each rotor, employing a direct excitation $1 D$ ${ }^{13} \mathrm{C}$ experiment for quantification. Experimental intensities are normalized using the same method as described previously (Xue et al. 2018). B) Simulated proton lineshapes for the methyl groups $L 34 \delta 1$ and $V 44 \gamma 2$. All simulations were carried out assuming a MAS frequency of $110 \mathrm{kHz}$ and an external magnetic field of $1 \mathrm{GHz}$. Intensities are normalized according to the number of protons. C) Simulated $\mathrm{CH}_{3} / \mathrm{CHD}_{2}$ intensity ratio as a function of MAS for $\mathrm{V} 44 \mathrm{\gamma} 2$. The methyl group of $\mathrm{V} 44 \mathrm{Y} 2$ is located in the core of the protein and experiences the highest proton density. D) MAS frequency necessary to reach equal intensity in $\mathrm{CH}_{3}$ (red) and $\mathrm{CH}_{2} \mathrm{D}$ (black) with respect to $\mathrm{CHD}_{2}$ selectively methyl protonated $\mathrm{SH} 3$ samples assuming a $B_{0}$ field of $1 \mathrm{GHz}$.

For L34, CH3 labelling yields a better sensitivity already above a MAS rotation frequency of $15 \mathrm{kHz}$ in comparison to $\mathrm{CHD}_{2}$ labelling (Figure 3), if we assume the same polarization transfer efficiency. For V44, however, $\mathrm{CH}_{3}$ labelling will not be beneficial below a MAS frequency of $125 \mathrm{kHz}$ with respect to the $\mathrm{CHD}_{2}$ labelled sample. The situation is even worse for $\mathrm{CH}_{2} \mathrm{D}$ labelled samples for which the break-even in comparison to $\mathrm{CHD}_{2}$ is expected above MAS rotation frequencies of $175 \mathrm{kHz}$. 
We would like to point out here that the high proton density in $\mathrm{CH}_{3}$ labelled microcrystalline samples can have an impact on the sensitivity of the experiment and might prevent the detection of a $\mathrm{CH}_{3}$ labelled methyl group in the core of a protein structure. Care has to be taken in particular in experiments aiming at a structural analysis. Missing methyl cross peaks might result in a lack of short-range distance restraints that are potentially essential to define the geometry of the core of the protein structure.

\section{Conclusion}

We have shown that a MAS rotation frequency above $110 \mathrm{kHz}$ is necessary to yield higher sensitivity for all methyl resonances in $\mathrm{CH}_{3}$ selectively methyl protonated microcrystalline samples in comparison to their $\mathrm{CHD}_{2}$ labelled counter parts. We believe that the obtained results will be in particular of interest for the design of experiments involving very large and ordered protein complexes for which sensitivity is limiting, and for which an additional gain in sensitivity would be desirable.

\section{Materials and methods}

The perdeuterated, selectively methyl protonated sample of the micro-crystalline $\mathrm{SH} 3$ domain was prepared as described previously (Agarwal et al. 2008). In brief, expression was carried out in $100 \% \mathrm{D}_{2} \mathrm{O}$ M9 medium, supplemented with ${ }^{15} \mathrm{~N}$ ammonium chloride and $\mathrm{u}-\left[{ }^{2} \mathrm{H},{ }^{13} \mathrm{C}\right]-\mathrm{D}$-glucose. a-ketoisovalerate (2-keto-3-(methyl$\mathrm{d}_{3}$ )-butyric acid-4- ${ }^{13} \mathrm{C}$ sodium salt, Sigma-Aldrich) $\left(-\mathrm{CH}_{3}\right.$ and $-\mathrm{CHD}_{2}$ labelled) was added to the M9 medium $1 \mathrm{~h}$ prior to induction with $1 \mathrm{mM}$ IPTG (at $\mathrm{OD}_{600}$ 0.5-0.6). Subsequent to overnight expression, the $\mathrm{SH} 3$ domain was purified via anion exchange and size exclusion chromatography as described before. For crystallization, pure protein was lyophilized and dissolved in $100 \% \mathrm{D}_{2} \mathrm{O}$ (final concentration: 8-10 mg/ml). Ammonium sulfate (dissolved in $100 \% \mathrm{D}_{2} \mathrm{O}$ ) was added to a final concentration of 100 $\mathrm{mM}$ and the $\mathrm{pH}$ was adjusted to 8.0 by adding $\mathrm{NaOD}$.

All NMR experiments were carried out using a $0.7 \mathrm{~mm} \mathrm{H} / \mathrm{C} / \mathrm{N}$ triple resonance MAS probe operating at a static magnetic field of $23.6 \mathrm{~T}$ ( $1 \mathrm{GHz}{ }^{1} \mathrm{H}$ Larmor frequency). As the sample was recrystallized from $100 \% \mathrm{D}_{2} \mathrm{O}$, no solvent suppression was employed. For all experiments, the effective sample temperature was adjusted to be the same, using DSS and the residual water signal for calibration (Linser et al. 2007). The pulse sequences used to quantify the transfer efficiency are reported in the Supplementary 
Material (Figure S3). The optimised ${ }^{1} \mathrm{H}-{ }^{13} \mathrm{C}$ and ${ }^{13} \mathrm{C}-{ }^{1} \mathrm{H} \mathrm{CP}$ conditions at $1 \mathrm{GHz}$ field are as follows: at $106 \mathrm{kHz}$ MAS $\left(60 \mathrm{kHz}\right.$ on ${ }^{13} \mathrm{C}, 177 \mathrm{kHz}$ on $\left.{ }^{1} \mathrm{H}\right)$, at $90 \mathrm{kHz}$ MAS $(60 \mathrm{kHz}$ on ${ }^{13} \mathrm{C}$ and $160 \mathrm{kHz}$ on ${ }^{1} \mathrm{H}$ ) and at $70 \mathrm{kHz}$ MAS $\left(50 \mathrm{kHz}\right.$ on ${ }^{13} \mathrm{C}$ and $130 \mathrm{kHz}$ on $\left.{ }^{1} \mathrm{H}\right)$. In all cases, ${ }^{1} \mathrm{H}$ RF amplitude during Hartmann-Hahn matching was varied between $90 \%$ to $100 \%$ of the nominal values whereas constant amplitude was used for ${ }^{13} \mathrm{C}$. The contact times for ${ }^{13} \mathrm{C}-{ }^{1} \mathrm{H}$ were set to $500 \mu$ s for both samples, whereas for ${ }^{1} \mathrm{H}-{ }^{13} \mathrm{C}$ transfer, $500 \mu$ s and $1.5 \mathrm{~ms}$ contact times were chosen for $\mathrm{CH}_{3}$ and $\mathrm{CHD}_{2}$ samples, respectively.

\section{Acknowledgement}

This work was performed in the framework of the SFB-1035 (Project B07; German Research Foundation, DFG). We acknowledge support from the HelmholtzGemeinschaft, the Deutsche Forschungsgemeinschaft (DFG, Grant Re1435), the Center for Integrated Protein Science Munich (CIPS-M), the CNRS (IR-RMN FR3050), the European Research Council (ERC) (ERC-2014-CoG "P-MEM-NMR" GA n 648974) and by the EU access project iNext (GA 653706).

\section{References}

Agarwal V, Penzel S, Szekely K, Cadalbert R, Testori E, Oss A, Past J, Samoson A, Ernst M, Bockmann A, Meier BH (2014) De Novo 3D Structure Determination from Sub-milligram Protein Samples by Solid-State $100 \mathrm{kHz}$ MAS NMR Spectroscopy. Angewandt Chem Int Edt 53:12253-12256

Agarwal V, Xue Y, Reif B, Skrynnikov NR (2008) Protein side-chain dynamics as observed by solution- and solid-state NMR: a similarity revealed. J Am Chem Soc 130:16611-16621

Andreas LB, Jaudzems K, Stanek J, Lalli D, Bertarello A, Marchand TL, Cala-De Paepe D, Kotelovica S, Akopjana I, Knott B, Wegner S, Engelke F, Lesage A, Emsley L, Tars K, Herrmann T, Pintacuda G (2016) Structure of fully protonated proteins by proton-detected magic-angle spinning NMR. Proc Natl Acad Sci USA 113:9187-9192 Asami S, Reif B (2012) Assignment strategies for aliphatic protons in the solid-state in randomly protonated proteins. J Biomol NMR 52:31-39

Asami S, Reif B (2013) Proton-Detected Solid-State NMR Spectroscopy at Aliphatic Sites: Application to Crystalline Systems. Accounts of Chemical Research 46:20892097

Asami S, Schmieder P, Reif B (2010) High resolution 1H-detected solid-state NMR spectroscopy of protein aliphatic resonances: access to tertiary structure information. Journal of the American Chemical Society 132:15133-15135

Bak M, Rasmussen JT, Nielsen NC (2000) SIMPSON: A General Simulation Program for Solid-State NMR Spectroscopy. Journal of Magnetic Resonance 147:296-330 
Barbet-Massin E, Huang C-T, Daebel V, Hsu S-TD, Reif B (2015) Site-Specific SolidState NMR Studies of "Trigger Factor" in Complex with the Large Ribosomal Subunit 50S. Angewandte Chemie International Edition 54:4367-4369

Barbet-Massin E, Pell AJ, Retel JS, Andreas LB, Jaudzems K, Franks WT, Nieuwkoop AJ, Hiller M, Higman V, Guerry P, Bertarello A, Knight MJ, Felletti M, Le Marchand T, Kotelovica S, Akopjana I, Tars K, Stoppini M, Bellotti V, Bolognesi M, Ricagno S, Chou JJ, Griffin RG, Oschkinat H, Lesage A, Emsley L, Herrmann T, Pintacuda G (2014) Rapid Proton-Detected NMR Assignment for Proteins with Fast Magic Angle Spinning. J Am Chem Soc 136:12489-12497

Barbet-Massin E, van der Sluis E, Musial J, Beckmann R, Reif B (2018) Reconstitution of Isotopically Labeled Ribosomal Protein L29 in the 50S Large Ribosomal Subunit for Solution-State and Solid-State NMR. Protein Complex Assembly, pp 87-100

Bockmann A, Ernst M, Meier BH (2015) Spinning proteins, the faster, the better? J Magn Reson 253:71-79

Bodenhausen G, Ruben DJ (1980) Natural abundance nitrogen-15 NMR by enhanced heteronuclear spectroscopy. Chemical Physics Letters 69:185-189

Cala-De Paepe D, Stanek J, Jaudzems K, Tars K, Andreas LB, Pintacuda G (2017) Is protein deuteration beneficial for proton detected solid-state NMR at and above $100 \mathrm{kHz}$ magic-angle spinning? Solid State Nuclear Magnetic Resonance 87:126-136 Chevelkov V, Faelber K, Schrey A, Rehbein K, Diehl A, Reif B (2007) Differential Line Broadening in MAS solid-state NMR due to Dynamic Interference. J Am Chem Soc 129:10195-10200

Chevelkov V, Rehbein K, Diehl A, Reif B (2006) Ultrahigh resolution in proton solidstate NMR spectroscopy at high levels of deuteration. Angew Chem Int Edit 45:38783881

Ishii Y, Yesinowski JP, Tycko R (2001) Sensitivity Enhancement in Solid-State13C NMR of Synthetic Polymers and Biopolymers by1H NMR Detection with High-Speed Magic Angle Spinning. Journal of the American Chemical Society 123:2921-2922

Knight MJ, Webber AL, Pell AJ, Guerry P, Barbet-Massin E, Bertini I, Felli IC, Gonnelli L, Pierattelli R, Emsley L, Lesage A, Herrmann T, Pintacuda G (2011) Fast Resonance Assignment and Fold Determination of Human Superoxide Dismutase by High-Resolution Proton-Detected Solid-State MAS NMR Spectroscopy. Angew Chem Int Edt 50:11697-11701

Kurauskas V, Crublet E, Macek P, Kerfah R, Gauto DF, Boisbouvier J, Schanda P (2016) Sensitive proton-detected solid-state NMR spectroscopy of large proteins with selective $\mathrm{CH} 3$ labelling: application to the $50 \mathrm{~S}$ ribosome subunit. Chemical Communications 52:9558-9561

Lewandowski JR, Dumez JN, Akbey U, Lange S, Emsley L, Oschkinat H (2011) Enhanced Resolution and Coherence Lifetimes in the Solid-State NMR Spectroscopy of Perdeuterated Proteins under Ultrafast Magic-Angle Spinning. J Phys Chem Lett 2:2205-2211

Linser R, Chevelkov V, Diehl A, Reif B (2007) Sensitivity Enhancement Using Paramagnetic Relaxation in MAS Solid State NMR of Perdeuterated Proteins. J Magn Reson 189:209-216

Mance D, Sinnige T, Kaplan M, Narasimhan S, Daniëls M, Houben K, Baldus M, Weingarth M (2015) An Efficient Labelling Approach to Harness Backbone and SideChain Protons in1H-Detected Solid-State NMR Spectroscopy. Angewandte Chemie International Edition 54:15799-15803

Maricq MM, Waugh JS (1979) NMR in rotating solids. The Journal of Chemical Physics 70:3300-3316 
Maudsley AA, Müller L, Ernst RR (1977) Cross-correlation of spin-decoupled NMR spectra by heteronuclear two-dimensional spectroscopy. Journal of Magnetic Resonance (1969) 28:463-469

McDermott AE, Creuzet FJ, Kolbert AC, Griffin RG (1992) High-resolution magicangle-spinning NMR spectra of protons in deuterated solids. Journal of Magnetic Resonance (1969) 98:408-413

Nieuwkoop AJ, Franks WT, Rehbein K, Diehl A, Akbey Ü, Engelke F, Emsley L, Pintacuda G, Oschkinat H (2015) Sensitivity and resolution of proton detected spectra of a deuterated protein at 40 and $60 \mathrm{kHz}$ magic-angle-spinning. Journal of Biomolecular NMR 61:161-171

Penzel S, Oss A, Org M-L, Samoson A, Böckmann A, Ernst M, Meier BH (2019) Spinning faster: protein NMR at MAS frequencies up to $126 \mathrm{kHz}$. Journal of Biomolecular NMR 73:19-29

Penzel S, Smith AA, Agarwal V, Hunkeler A, Org ML, Samoson A, Bockmann A, Ernst M, Meier BH (2015) Protein resonance assignment at MAS frequencies approaching $100 \mathrm{kHz}$ : a quantitative comparison of J-coupling and dipolar-couplingbased transfer methods. J Biomol NMR 63:165-186

Pines A, Gibby MG, Waugh JS (1973) Proton-Enhanced Nmr of Dilute Spins in Solids. J Chem Phys 59:569-590

Reif B (2012) Ultra-high resolution in MAS solid-state NMR of perdeuterated proteins: Implications for structure and dynamics. J Magn Reson 216:1-12

Reif B, Jaroniec CP, Rienstra CM, Hohwy M, Griffin RG (2001) 1H-1H MAS Correlation Spectroscopy and Distance Measurements in a Deuterated Peptide. Journal of Magnetic Resonance 151:320-327

Saalwächter K (2005) Sensitivity enhancement by inverse detection in solids. NMR Spectroscopy of Biological Solids: 151-175

Samoson A, Tuherm T, Past J, Reinhold A, Anupold T, Heinmaa I (2005) New horizons for magic-angle spinning NMR. Topics in current chemistry 246:15-31

Schubeis T, Le Marchand T, Andreas LB, Pintacuda G (2018) 1H magic-angle spinning NMR evolves as a powerful new tool for membrane proteins. Journal of Magnetic Resonance 287:140-152

Sprangers R, Kay LE (2007) Probing supramolecular structure from measurement of methyl (1)H-(13)C residual dipolar couplings. Journal of the American Chemical Society 129:12668-12669

Sprangers R, Velyvis A, Kay LE (2007) Solution NMR of supramolecular complexes: providing new insights into function. Nature methods 4:697-703

Stanek J, Andreas LB, Jaudzems K, Cala D, Lalli D, Bertarello A, Schubeis T, Akopjana I, Kotelovica S, Tars K, Pica A, Leone S, Picone D, Xu ZQ, Dixon NE, Martinez D, Berbon M, El Mammeri N, Noubhani A, Saupe S, Habenstein B, Loquet A, Pintacuda G (2016) NMR Spectroscopic Assignment of Backbone and Side-Chain Protons in Fully Protonated Proteins: Microcrystals, Sedimented Assemblies, and Amyloid Fibrils. Angew Chem Int Ed Engl 55:15503-15509

Stock A, Stöppler D, Macpherson A, Smith-Penzel S, Basse N, Lecomte F, Deboves H, Taylor RD, Norman T, Porter J, Waters LC, Westwood M, Cossins B, Cain K, White J, Griffin R, Prosser C, Kelm S, Sullivan AH, Fox D, Carr MD, Henry A, Taylor R, Meier BH, Oschkinat H, Lawson AD (2018) Insight into small molecule binding to the neonatal $\mathrm{Fc}$ receptor by X-ray crystallography and $100 \mathrm{kHz}$ magic-angle-spinning NMR. PLOS Biology 16:e2006192 
Tošner Z, Andersen R, Stevensson B, Edén M, Nielsen NC, Vosegaard T (2014) Computer-intensive simulation of solid-state NMR experiments using SIMPSON. Journal of Magnetic Resonance 246:79-93

Vasa SK, Singh H, Grohe K, Linser R (2019) Assessment of a Large Enzyme-Drug Complex by Proton-Detected Solid-State NMR Spectroscopy without Deuteration. Angewandte Chemie International Edition 58:5758-5762

Xue K, Sarkar R, Motz C, Asami S, Camargo DCR, Decker V, Wegner S, Tosner Z, Reif B (2017) Limits of Resolution and Sensitivity of Proton Detected MAS Solid-State NMR Experiments at $111 \mathrm{kHz}$ in Deuterated and Protonated Proteins. Sci Rep 7:7444 Xue K, Sarkar R, Motz C, Asami S, Decker V, Wegner S, Tosner Z, Reif B (2018) Magic-Angle Spinning Frequencies beyond $300 \mathrm{kHz}$ Are Necessary To Yield Maximum Sensitivity in Selectively Methyl Protonated Protein Samples in Solid-State NMR. The Journal of Physical Chemistry C 122:16437-16442

Zorin VE, Brown SP, Hodgkinson P (2006) Origins of linewidth in 1H magic-angle spinning NMR. J Chem Phys 125:144508 


\section{Supporting Information}

\section{for the manuscript}

\section{MAS dependent Sensitivity of different Isotopomers in selectively Methyl protonated Protein Samples in the solid State}

Kai Xue, ${ }^{\text {a }}$ Riddhiman Sarkar, ${ }^{\text {a,b* }}$ Zdenek Tosner, ${ }^{c}$ Daniela Lalli, ${ }^{d}$ Carina Motz, ${ }^{b}$ Benita Koch, ${ }^{b}$ Guido Pintacuda ${ }^{d, 1}$ and Bernd Reif ${ }^{a, b_{*}}$

June 24, 2019

${ }^{a}$ Helmholtz-Zentrum München (HMGU), Deutsches Forschungszentrum für Gesundheit und Umwelt, Ingolstädter Landstr. 1, 85764 Neuherberg, Germany

${ }^{\mathrm{b}}$ Munich Center for Integrated Protein Science (CIPS-M) at Department Chemie, Technische Universität München (TUM), Lichtenbergstr. 4, 85747 Garching,

\section{Germany}

${ }^{c}$ Department of chemistry, Faculty of Science, Charles University, Hlavova 8, 12842

Praha 2, Czech Republic

${ }^{d}$ Centre de Résonance Magnétique Nucléaire a Très hauts Champs (FRE 2034 -

CNRS, Ecole Normale Supérieure de Lyon, Université Claude Bernard Lyon 1), Université de Lyon, 5 rue de la Doua, 69100 Villeurbanne, France

\#Present address: Dipartimento di Scienze e Innovazione Tecnologica, Università del Piemonte Orientale Amedeo Avogadro, viale Teresa Michel, 15121 Alessandria, Italia

To whom correspondence should be addressed: reif@tum.de, riddhiman.sarkar@helmholtz-muenchen.de 
A

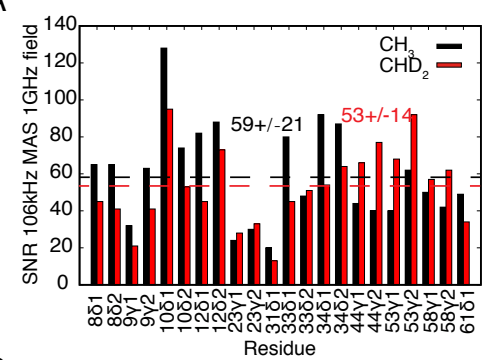

C

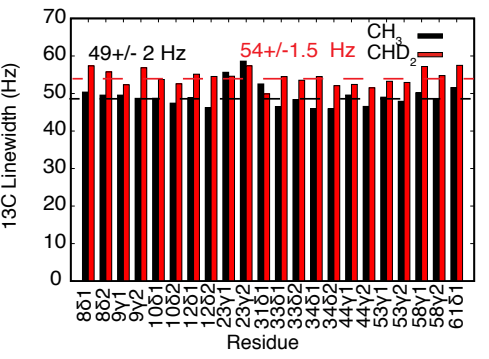

$\mathrm{B}$
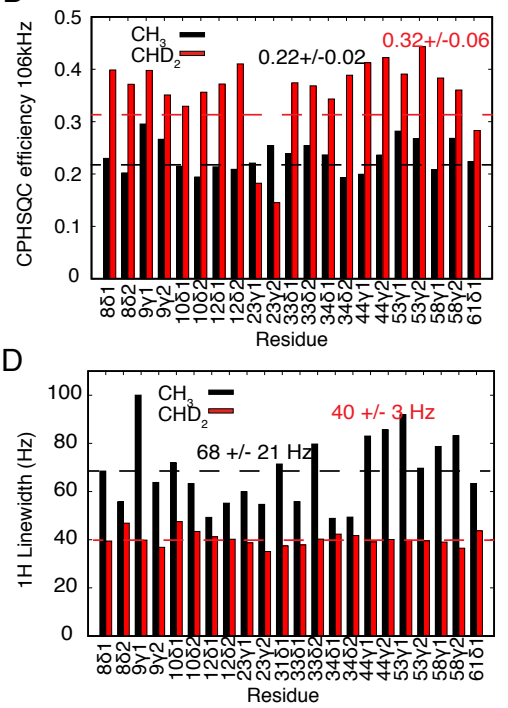

Figure S1: Intensity analysis for spectra obtained for $\mathrm{CH}_{3}$ and $\mathrm{CHD}_{2}$ labelled $\mathrm{SH} 3$ domain protein. CP based HSQC spectra were obtained at $106 \mathrm{kHz}$ MAS and $1 \mathrm{GHz} B_{0}$ field. Raw data were processed with $35 \mathrm{~ms}$ acquisition in carbon detection. In proton dimension, no window function is given, $\mathrm{CH}_{3}$ was processed with $20 \mathrm{~ms}$ acquisition and $\mathrm{CHD}_{2}$ was processed with $50 \mathrm{~ms}$ acquisition. Square sine bell (QSINE as implemented in Topspin Bruker) window function was applied for apodization in the indirect dimension. All peaks were nicely resolved. (Measured site-specific proton $\mathrm{T}_{2}$ is $6 \mathrm{~ms}$ on average for $\mathrm{CH}_{3}$ and $50 \mathrm{~ms}$ on average for $\left.\mathrm{CHD}_{2}\right)$. The mean efficiency of $2 \mathrm{CP}$ steps together $\left({ }^{1} \mathrm{H}->{ }^{13} \mathrm{C}\right.$ and $\left.{ }^{13} \mathrm{C}->{ }^{1} \mathrm{H}\right)$ amounts to 0.32 and 0.22 for $\mathrm{CHD}_{2}$ and $\mathrm{CH}_{3}$ labelled samples, respectively (B) measured by employing pulse sequence described in Figure S3A. Of note, no scaling of intensities due to sample amount was performed in $A$ as done in Figure $1 D$ in the main manuscript. 


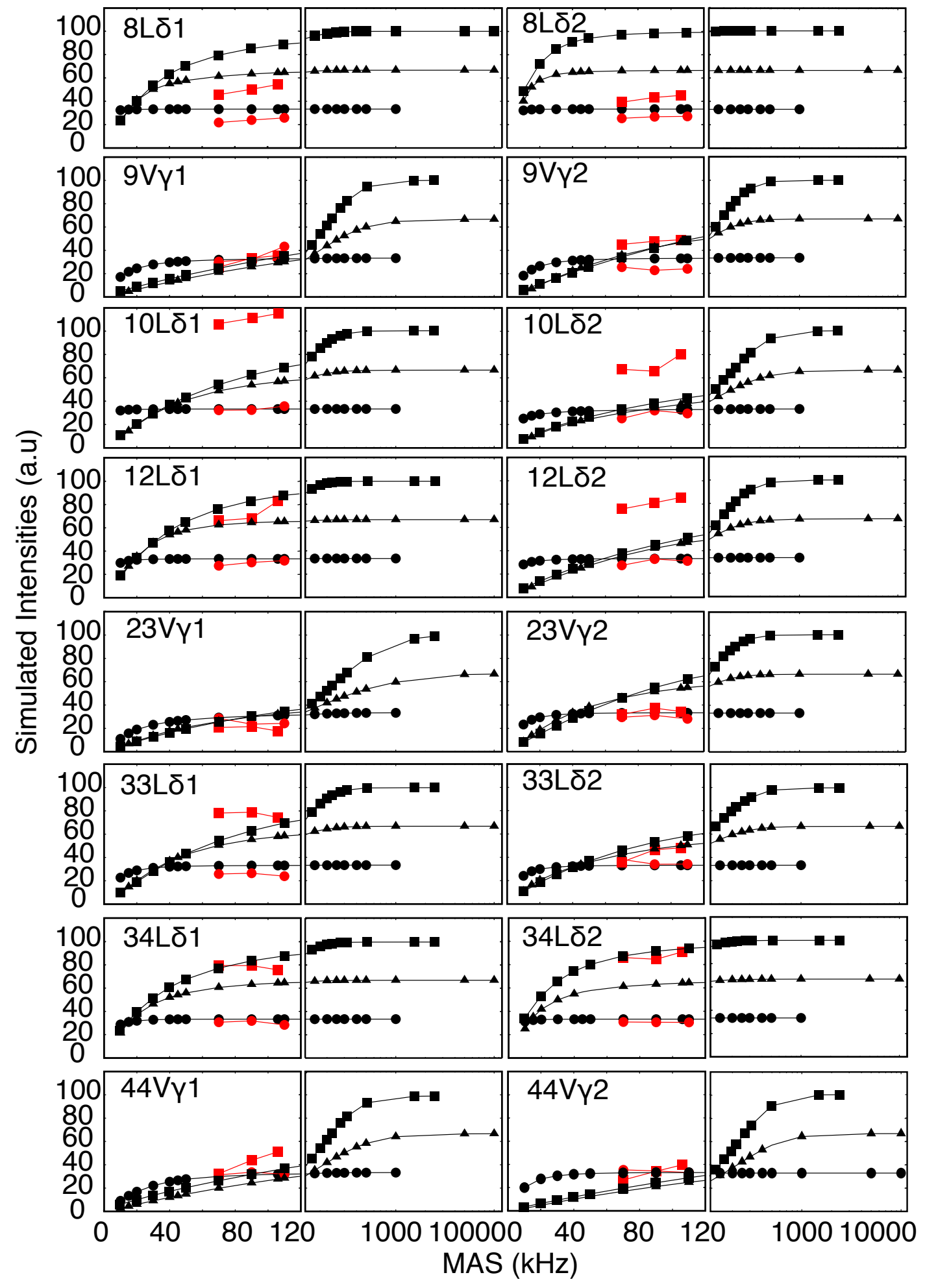

Figure S2: to be continued 


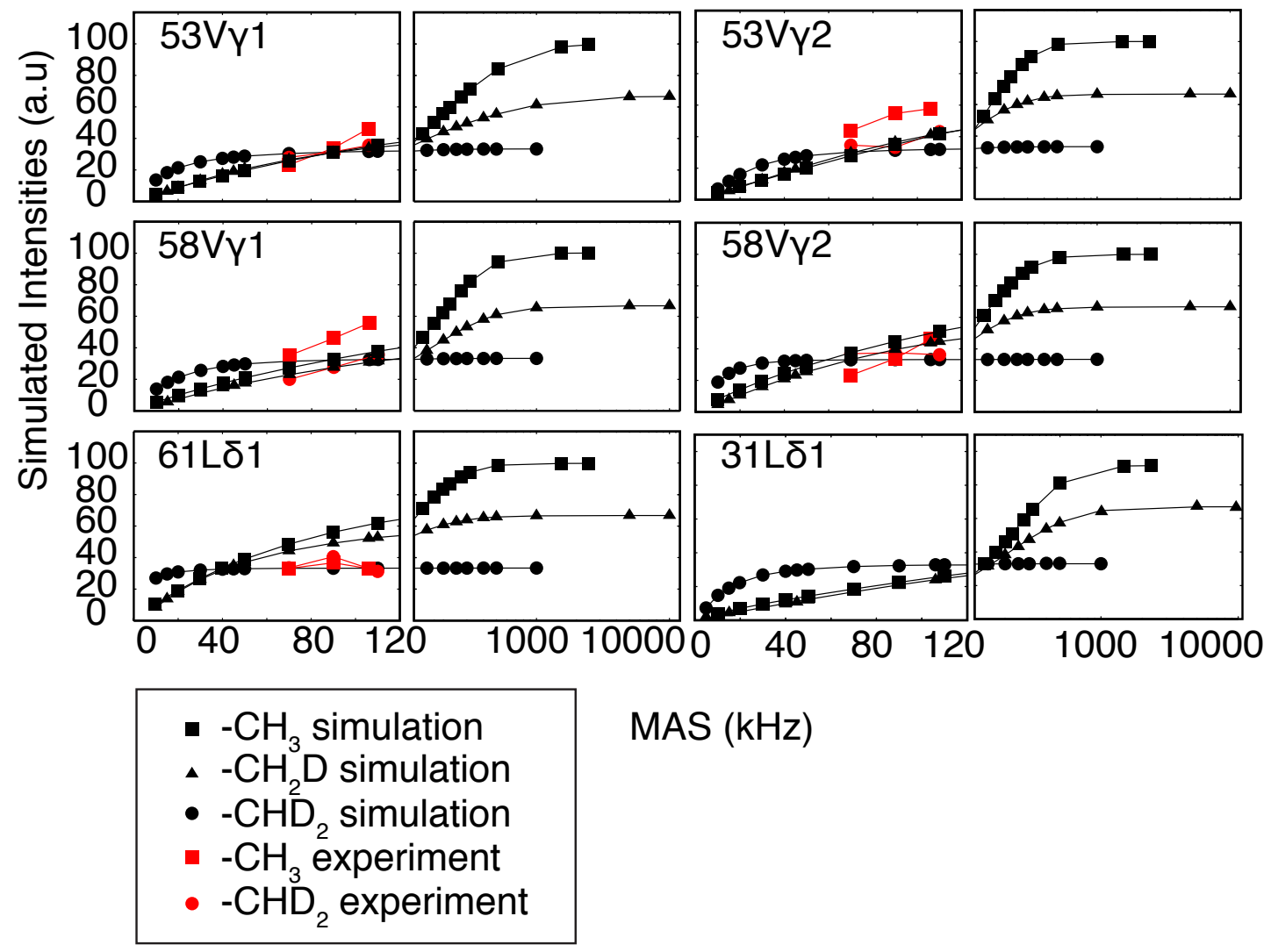

Figure S2: $H S Q C{ }^{1} H$ spectral intensities for all valine and leucine methyl groups $\alpha$-spectrin SH3 as a function of MAS frequency. The experimental intensities were corrected for the experimental CP transfer efficiency. Experimental normalization method is the same as mentioned in previous publication.

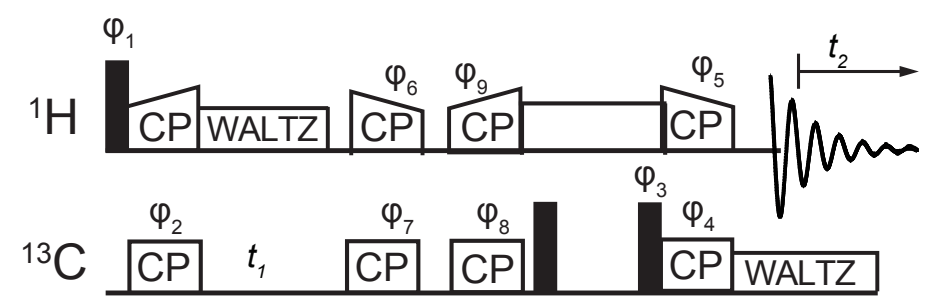

$$
\begin{aligned}
& \varphi_{1}=\mathrm{y},-\mathrm{y} \quad \varphi_{2}=\mathrm{y} \quad \varphi_{3}=\mathrm{x}, \mathrm{x},-\mathrm{x},-\mathrm{x} \quad \varphi_{4}=\mathrm{y} \quad \varphi_{5}=4(\mathrm{y}) 4(-\mathrm{y}) \\
& \varphi_{6}=\mathrm{x} \quad \varphi_{7}=\mathrm{y} \quad \varphi_{8}=\mathrm{y} \quad \varphi_{9}=\mathrm{x} \\
& \varphi_{\mathrm{R}}=,-\mathrm{y},-\mathrm{y}, \mathrm{y},-\mathrm{y}, \mathrm{y}, \mathrm{y},-\mathrm{y}
\end{aligned}
$$

Figure S3: Pulse sequences for residue specific Dipolar coupling based cross polarization efficiency. 


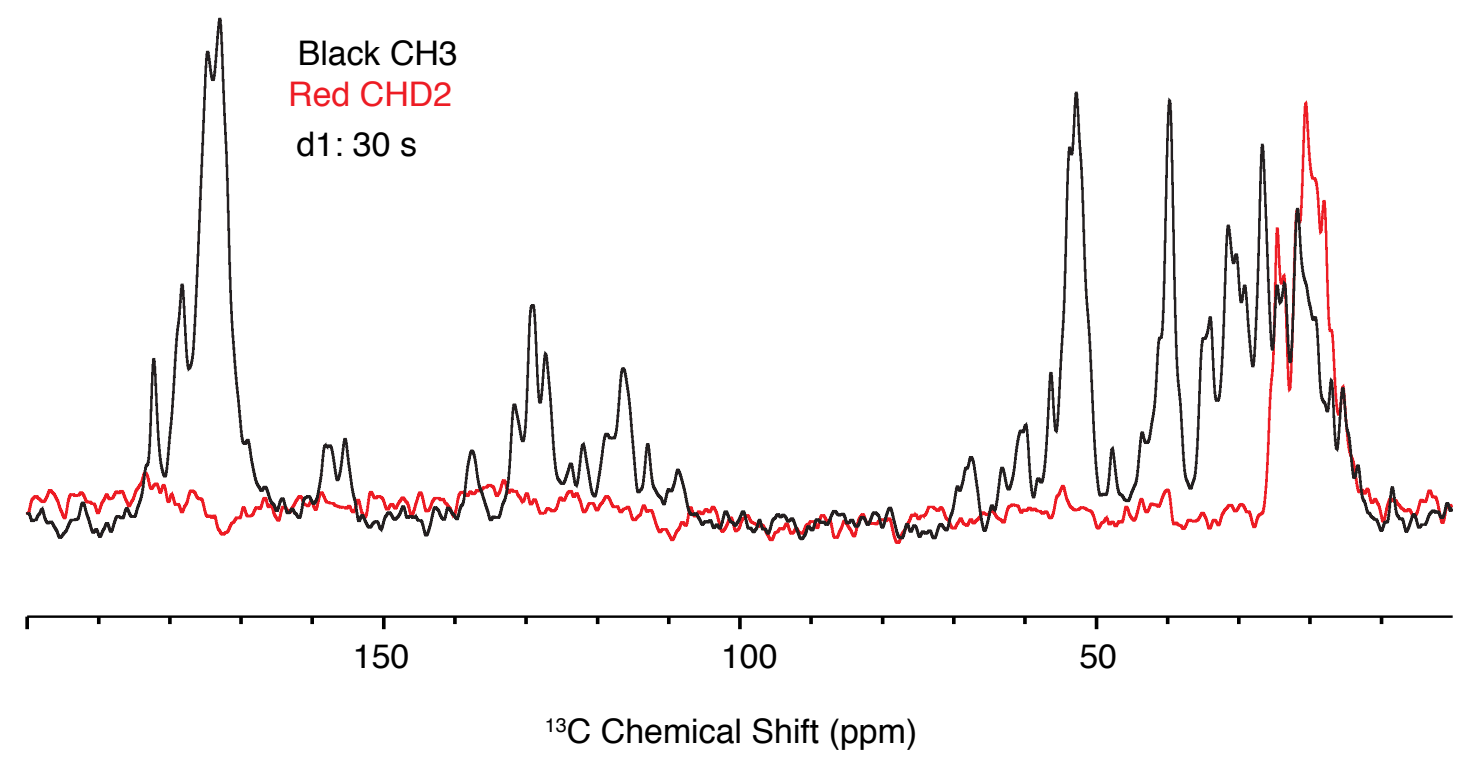

Figure S4: Bloch decay spectra to quantify sample amounts in $\mathrm{CH} 3$ and $\mathrm{CHD} 2$ labelled proteins in the two different rotors. The amount is judged based only on the methyl region of the spectra. 